\title{
Changes in Some Parameters of Salting Brazilian Freshwater Fish Effect of Aqueous Extract of Basil
}

\author{
Graziele Gustinelli ${ }^{1}$, Thiago Tetsuo Ushizima ${ }^{2}$ and Léa Silvia Sant'Ana ${ }^{1}$ \\ 1. Aquaculture Center, São Paulo State University, São Paulo, Brazil, Box 14884-900, Via de Acesso Professor Paulo Donato \\ Castellane, s/n-Vila Industrial, Jaboticabal-SP, Brazil \\ 2. Mar \& Terra Ind. Com de pescados S/A, Research and Development Division, Mato Grosso do Sul, Brazil
}

\begin{abstract}
Salting is a traditional process to preserve food, while news species have been salted showing good results. However, salt accelerates lipid oxidation, influencing shelf-life of salted products. Using of antioxidants increases salted and/or desalted products shelf-life. Among the antioxidants employed in food industry spices have shown satisfactory results. In this work aqueous basil extract (Ocimunbasilicum) in pintachara salt was used. Pintachara is a hybrid of pintado and cachara (genus Pseudoplatystoma) whose flesh is much appreciated, being desirable to develop new product of this fish. The aqueous basil extract was used in a brine salt, and process was carried out with a control treatment. Samples were obtained during salting in 1, 14, 24, 36, 48 hours. In each sample period it analyzed moisture, water activity, salt content e TBARS. The aqueous basil extract interfered in salting processes and showed antioxidant action in this process. Practical applications: Brazilian consumers appreciate salted fish, as influence of Portuguese culture. There are some typical regional products, such as the pantaneiro cod, which consists on catfish from Pantanal that is salted as cod. The development of hybrids from native fishes in aquaculture leads to higher lipid content in the hybrids and the addition of natural antioxidants during salting process increases the product shelf-life and keeps the sensorial properties.
\end{abstract}

Key words: Pintachara, salting,basil, antioxidant.

\section{Introduction}

Salting of fish is a traditional preservation method that has been used for centuries. The salt processing consists of transporting salt into food structures while water flows away of them [1]. Due to changes during salting in tissue structure and composition, salting enables a stable food production, which can be conserved for months [2]. Salt, as drying, reduces water activity $[3,4]$. Water activity includes free water, water bounds ions, proteins and carbohydrates [5]. Water activity value represents strength intensity that links water to non-aqueous components [6].

Dry salted Atlantic cod (Gadusmorhua) is one of the largest export products from Iceland and Norway and the major markets are in Southern Europe and Latin America [7]. Others species proved suitable and

Corresponding author: Graziele Gustinelli, $\mathrm{PhD}$ student, research field: food processing. are salted as herring [8,9]; anchovy [10]; tuna [11] and Nile tilapia $[12,13]$. Traditionally, in the Pantanal region (Brazil), catfish of the genus Pseudoplatystoma are salted, being marketed as "bacalhau pantaneiro".

Pseudoplatystoma species are considered to be high-quality products, which occupied a large portion of Brazilian fish market due to their meaty features, such as attractive coloration, firm texture, subtle taste, low fat content and absence of intramuscular spines, they are adequate for a wide range of recipes and process [14].

The artificial production of interspecific hybrids consists in a classical method of genetic improvement for aquaculture programs [15]. Pintachara is a hybrid between catfish species, a female of Pseudoplatystoma corruscans (pintado) and a male of Pseudoplatystoma reticulatum (cachara) [16]. These hybrids have advantages in aquaculture compared to your parenting as better growing [17]. The hybrid 
pintachara has a lipid content of $20 \%$ and $50 \%$ higher when compared to the unhybridized fish pintado and cachara, respectively from rivers, i.e. wild and cultivated.

Lipid oxidation depends on different factors, such as amount of lipid present, the degree of unsaturated fatty acids in the muscle, salt composition and conditions during salting and storage [18]. Salt increases lipid oxidation [3].

Crude extracts of fruits, herbs, vegetables, cereals, and other plants materials rich in phenolic are increasingly of interest in the food industry because they retard oxidative degradation of lipids and thereby improve the quality and nutritional value of food [19]. Salt increases lipid oxidation [3].

Basil (Ocimum basilicum), a member of the Lamiaceae family, is known as aromatic plant and medicinal plant and is widely cultivated in many countries [20, 21]. Basil has high levels of antioxidants and its extract could be an interesting source of natural antioxidants [22].

The purpose of this study was to verify the antioxidant effect of aqueous extract of basil in mass transfer phenomena, based on analysis and changes in pintachara properties throughout salting process.

\section{Materials and Methods}

\subsection{Materials}

\subsubsection{Fish Samples}

Pintachara reared at the Mar \& Terra were slaughtered and then degutted and beheaded. After the fish were frozen at $-20{ }^{\circ} \mathrm{C}$, frozen fish was cut into two parts (bands) and for cutting bone a band saw machine (CAF, Rio Claro, Brazil) was used. The thaw was carried out in refrigerator for 24 hours.

\subsubsection{Aqueous Extract}

Basil was purchased in a local market. Plants were stored at $4{ }^{\circ} \mathrm{C}$ until added $50 \mathrm{~g}$ of leaves to $1 \mathrm{~L}$ of distilled water in blender (Arno, São Paulo, Brazil). After, the extract was strained through a sieve plastic.

\subsection{Methods}

\subsubsection{Salting}

Bands were cut in pieces with approximately $100 \mathrm{~g}$ each. Salting was carried out using 2 treatments (with and without basil extract) with 3 repetitions ( 5 fillets each). Brining salting was carried out for 1 hour. Brine was prepared in the proportion of $400 \mathrm{~g}$ of fine salt to $1 \mathrm{~L}$ of water. Two treatments were carried out, with and without basil extract $(10 \%$ of extract in brine). The next step was the pile salting. Salt was in a proportion of $1 / 3$ of fine salt to $2 / 3$ of coarse salt. Fillets were covered in alternating layers of fish and salt. The liquid extracted from muscle was allowed to drain away. The experiment was carried out for 48 hours and samples were collected in 1, 14, 24, 36 and 48 hours to analyze.

\subsubsection{Chemical Analysis}

Lipids were extracted using the method described by Folch, Lees \& Sloane Stanley [23]. After extraction, lipids were esterified according to Hartman \& Lago [24]. Gas chromatography was performed using a gas cromatograph (Shimadzu, Kyoto, Japan) equipped with a fused silica capillary column Supelcowax 10, $30 \mathrm{~m}, 0.25 \mathrm{~mm}$ internal diameter (Sigma-Aldrich Co. St Louis, MO, USA), a flame ionization detector, and a split injector. Moisture content was determined using method specific for fish (952.08) [25], drying for 4 hours in stove at $105{ }^{\circ} \mathrm{C}$. Lipid oxidation was assessed by measuring 2-thiobarbituric acid reactive substances (TBARS) with the extraction method described by Vyncke [26]. In this method malonaldehyde (MDA) forms a complex with 2-thiobarbituric acid (TBA). This complex was determined at $532 \mathrm{~nm}$ in a spectrophotometer (UV Mini 1240, Shimadzu, Tokyo, Japan). $A_{w}$ was measured at $25{ }^{\circ} \mathrm{C}$ using an water activity meter model 3TE $\left(\mathrm{A}_{\mathrm{w}}\right.$ 0.100-1.000 \pm 0.003 , Decagon Devices, USA). Samples were digested by nitric acid. Afterwards, sodium content was measured by atomic emission spectrometry using equipment Shimadzu, AA-6800, which uses quantitative 
measurement of the optical emission form excited atoms to determine analyte concentration. To calculate sodium in chloride, the conversion factor is 2.54 .

\subsubsection{Statistics}

Regression analysis and the obtained quadratic polynomial regression with equation are:

$$
y=\mathrm{a} x^{2}+\mathrm{b} x+\mathrm{c}
$$

where $y$ is the analyzed parameter $\left(\mathrm{A}_{\mathrm{w}}\right.$, moisture, $\mathrm{NaCl}$ content or TBARS) and $x$ is the salting time in hours.

\section{Results and Discussion}

The lipid content of the pintachara is high, approximately $10 \%$ (Table 1 ). This fact facilitates the lipid oxidation during salting. The wild fish of the Pseudoplatystoma species have a great variation of the lipid contents according to the seasonality, sex, age and available feeding. For example, in the wild cachara was found a lipid variation between $0.37 \%$ and $8.06 \%$ [27].

The fatty acid composition of "pintachara" flesh (Table 1) follows the pattern described by Strobel, Jahreis \& Kuhnt [28] for farmed fish, in which main lipid sources of feed are vegetable oils. Several studies have confirmed an increase of $\mathrm{C} 18$ fatty acids in the fillet of farmed fish through the use of vegetable oils in the feed [28-30]. In the present work the $\mathrm{C} 18$, oleic acid $(\mathrm{C} 18: 1 \omega 9)$ and linoleic acid $(\mathrm{C} 18: 2 \omega 6)$ fatty acids represent half of the fatty acids identified. The higher amount of oleic acid in farmed samples is due to its dominance in the commercial feed [31].

For $A_{w}$ there is an evident difference between treatment and control, with treatment showing $A_{w}$ values lesser than control, probably because basil extract has influenced water outflow (Fig. 1A). Nevertheless, moisture contents had almost the same results to both (Fig. 1B). Salt concentration in the muscle of pintachara increased throughout the brining process and affected both brining time and the basil aqueous extract addition (Fig. 1C). TBARS value has changed during salting process due to salt being a pro-oxidant, but samples with basil extract had lower values and showed a delay when compared to control (Fig. 1D). This is caused probably by antioxidants substances present in basil leaves. Aqueous extract of basil possessed a strong antioxidant activity, because this extract contains a highest amount of total phenolic contents and flavonoids [22, 32].

The $\mathrm{R}^{2}$ for samples with and without basil (Table 2) explains respectively $21.1 \%$ and $44.3 \%$ for $A_{w}, 30.1 \%$ and $57.4 \%$ for moisture content, $41.3 \%$ and $25.8 \%$ for salt content and finally, $28.3 \%$ and $52.8 \%$ for TBARS. The low $\mathrm{R}^{2}$ is related with external factors which influence analyzed results. Size and thickness could influence salt distribution and water flow output [5]. High fat content also influences water entrances for retarding water transfer due to their hydrophobic nature [5]. Second other strengths beyond diffusion [1] are responsible for mass transfer, as pressure gradients, water holding capacity, protein denaturation. As salting process reaches equilibrium strength evolved weakens [1].

The parameters analyzed decreased quickly in the first hours, mainly in the first 3-5 hours, similar to those obtained by other authors as Barat and co-workers [1] and Medina-Vivanco and co-workers [12]. In a second phase, mass transfer rates decrease

Table 1 Fatty acid composition of pintachara fish muscle (expressed as weight percent of total fatty acids).

\begin{tabular}{ll}
\hline $16: 0$ & $21.17 \pm 0.16$ \\
$18: 0$ & $8.65 \pm 0.10$ \\
$16: 1 \omega 7$ & $3.47 \pm 0.06$ \\
$18: 1 \omega 9$ & $35.47 \pm 0.03$ \\
$20: 1 \omega 9$ & $1.60 \pm 0.14$ \\
$18: 2 \omega 6$ & $13.71 \pm 0.04$ \\
$20: 4 \omega 6$ & $1.23 \pm 0.04$ \\
$18: 3 \omega 3$ & $0.87 \pm 0.01$ \\
$20: 5 \omega 3$ & $0.89 \pm 0.04$ \\
$22: 6 \omega 3$ & $3.48 \pm 0.20$ \\
\hline Lipids & $9.69 \pm 0.84$ \\
\hline Moisture content & $73.91 \pm 0.73$ \\
\hline
\end{tabular}



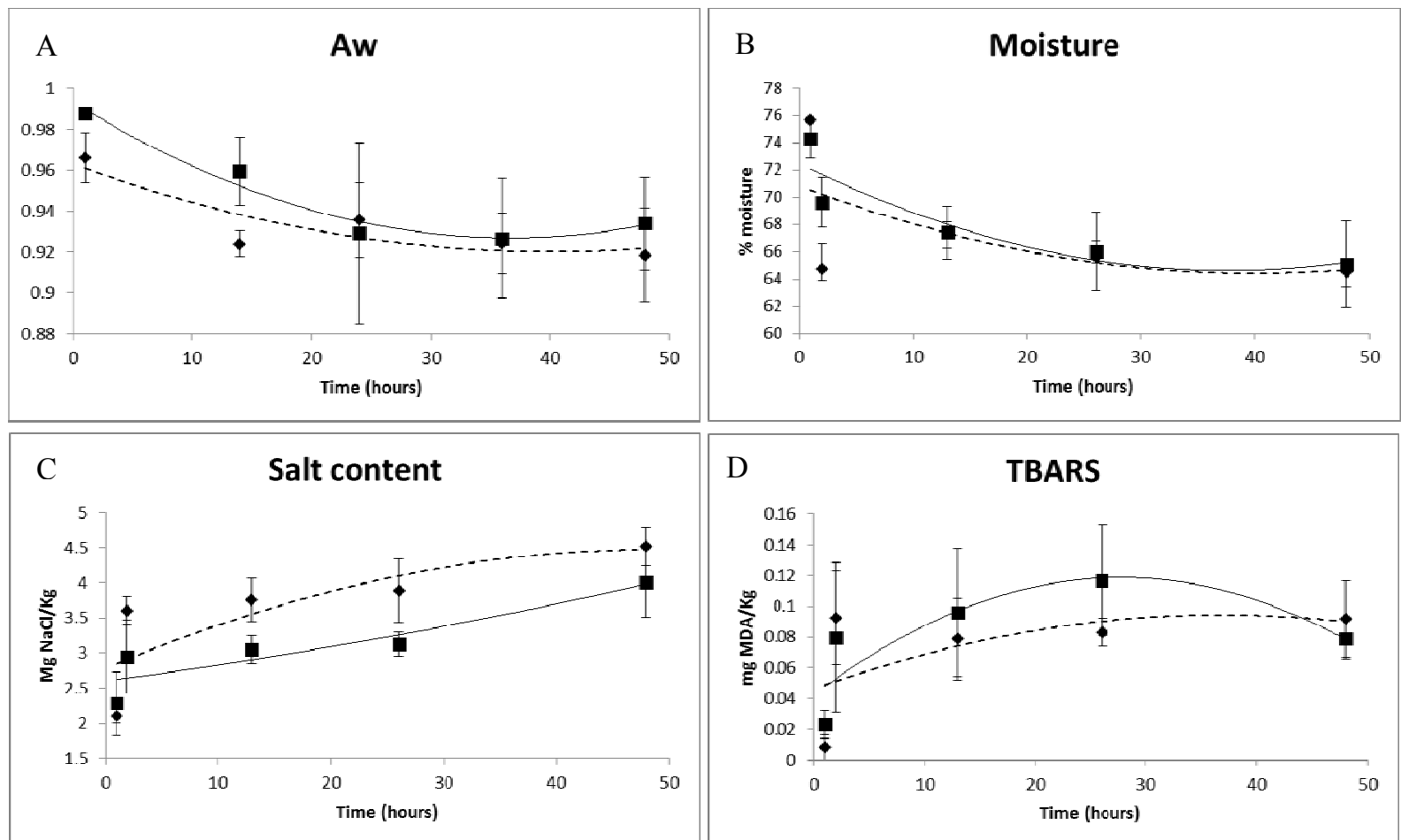

Fig. 1 Changes in (A) water activity; (B) moisture; (C) NaCl content and (D) TBARS of pintachara during salting process. With basil (dashed line) and without basil (solid line).

Table 2 Polynomial best-fit equation of parameters water activity; moisture; NaCl content and TBARS of pintachara during salting process.

\begin{tabular}{lllll}
\hline & \multicolumn{4}{c}{ Without basil } \\
\hline $\mathrm{A}_{\mathrm{w}}$ & $\mathrm{a}$ & $\mathrm{b}$ & $\mathrm{c}$ & $\mathrm{R}^{2}$ \\
$\mathrm{Moisture}$ & 0.9778 & $-3.881 \times 10^{-3}$ & $6.251 \times 10^{-5}$ & 0.4431 \\
$\mathrm{NaCl}$ & 72.495 & -0.4169 & 0.0056 & 0.5744 \\
$\mathrm{TBARS}$ & 6.626 & 0.0528 & 0.00043 & 0.2579 \\
& 0.042 & $5.496 \times 10^{-3}$ & $-9.883 \times 10^{-5}$ & 0.5279 \\
\hline $\mathrm{A}_{\mathrm{w}}$ & & & With basil & 0.2105 \\
$\mathrm{Moisture}$ & 0.945 & $-1.108 \times 10^{-3}$ & $1.155 \times 10^{-5}$ & 0.3013 \\
$\mathrm{NaCl}$ & 70.663 & -0.3088 & 0.00383 & 0.413 \\
TBARS & 2.774 & 0.0689 & -0.0007 & 0.283 \\
\hline
\end{tabular}

considerably showing a tendency to constant values.

Basil extract has retarded the rates for every parameter analyzed when compared to control samples. At the end of experiment, values had a trend to reach similar values with the equilibrium of salting. The outcome of salting process can be influenced by several factors, such as salting time, granulation of salt and addition of antioxidants [5]. These factors can lead to a hamper in water outflow, influencing the mass transfer and the behavior of all parameters analyzed.

\section{Conclusion}

Basil extract interfered in sating process, retarding mass transfers. This extract retarded water outflow and salt penetration. With respect to antioxidant action, basil aqueous extract showed to be efficient in salting. Basil is a good source of antioxidants and its use in food industry can be advantageous to extend self-life of salted products. 


\section{Acknowledgement}

The authors would like to thank the Brazilian National Council for Scientific and Technological Development-CNPq for providing a scholarship.

\section{References}

[1] Barat, J., Rodriguez-Barona, S., Andres, A., and Fito., P. 2003. "Cod Salting Manufacturing Analysis." Food Research International 36 (5): 447-53.

[2] Andrés, A., Rodriguez- Barona, S., Barat, J., and Fito, P. 2005. "Salted Cod Manufacturing: Influence of Salting Procedure on Process Yield and Product Characteristics." Journal of Food Engineering 69 (4): 467-71.

[3] Albarracin, W., Sanchez, I., Grau, R., and Barat, J. 2011. "Salt in Food Processing; Usage and Reduction: A Review." International Journal of Food Science and Technology 46 (7): 1329-36.

[4] Oliveira, H., Pedro, S., Nunes, M. L., Costa, R., and Vaz-Pires, P. 2012. "Processing of Salted Cod (Gadus spp.): A Review." Comprehensive Reviews in Food Science and Food Safety 11 (6): 546-64.

[5] Nunes, M. L., and Pedro, S. 2011. "Traditional Technologies: Fish Salting.” In Fish Technology: Science, Technology, Innovation and Legislation, edited by A. A. Gonçalves São Paulo: Atheneu, 155-6. (in Portuguese)

[6] Ordóñez, J. A., Cambero, M. I. R., Fernández, L. A., García, M. L. S., Minguillón, G. D. G. F., de la Hoz, L., and Selgas, M. D. C. 2005. "Water." In Food Technology, Volume 2: Food Components and Processing, edited by J. A. Ordóñez, M. I. R. Cambero, L. A. Fernández, M. L. S. García, G. D. G. F. Minguillón, L. de la Hoz, and M. D. C.Porto Alegre: Artmed, 21-32. (in Spanish)

[7] Gudjónsdóttir, M., Arason, S., and Rustad, T. 2011. "The Effects of Pre-salting Methods on Water Distribution and Protein Denaturation of Dry Salted and Rehydrated Cod-A Low-Field NMR Study." Journal of Food Engineering 104 (1): 23-9.

[8] Aro, T., Larmo, P., Backman, C., Kallio, H., and Tahvonen, R. 2005. "Fatty Acids and Fat-Soluble Vitamins in Salted Herring (Clupea harengus) Products." Journal of Agricultural and Food Chemistry 53 (5): 1482-8.

[9] Andersen, E., Andersen, M., and Baron, C. 2007. "Characterization of Oxidative Changes in Salted Herring (Clupea harengus) during Ripening." Journal of Agricultural and Food Chemistry 55 (23): 9545-53.

[10] Czerner, M., Tomas, M., and Yeannes, M. 2011. "Ripening of Salted Anchovy (Engraulis anchoita): Development of Lipid Oxidation, Colour and Other Sensorial Characteristics." Journal of the Science of Food and Agriculture 91 (4): 609-15.

[11] Barat, J., and Grau, R. 2009. "Thawing and Salting Studies of Dry-Cured Tuna Loins." Journal of Food Engineering 91 (3): 455-9.

[12] Medina-Vivanco, M. L., Sobral, P. J. A., and Hubinger, M. D. 2006. "Kinetic Aspects of Salting Tilapia Fillets Using Small Volumes of Brine." Brazilian Journal of Food Technology 9 (1): 9-17.

[13] Chaijan, M. 2011. "Physicochemical Changes of Tilapia (Oreochromis niloticus) Muscle during Salting." Food Chemistry 129 (3): 1201-10.

[14] Faustino, F., Nakaghi, L. S. O., Marques, C., Ganeco, L. N., and Makino, L. C. 2010 "Structural and Ultrastructural Characterization of the Embryonic Development of Pseudoplatystoma spp. Hybrids." The International Journal of Development Biology 54 (4): 723-30.

[15] Hashimoto, D. T., Prado, F. D., Foresti, F., and Porto-Foresti, F. 2016. "Molecular Identification of Intergenus Crosses Involving Catfish Hybrids: Risks for Aquaculture Production." Ichthyology 14 (2).

[16] Baggio, R. A., Moretti, C. B., Bialetzki, A., and Boeger, W. A. 2016. "Hybrids between Pseudoplatystoma corruscans and P. reticulatum (Siluriformes: Pimelodidae) Previously Reported in the Upper Paraná River Are Likely Escapes from Aquaculture Farms: Evidence from Microsatellite Markers.” Zoologia 33 (1): 1-6.

[17] Prado, F., Hashimoto, D., Senhorini, J., Foresti, F., and Porto-Foresti, F. 2012. "Detection of Hybrids and Genetic Introgression in Wild Stocks of Two Catfish Species (Siluriformes: Pimelodidae): The Impact of Hatcheries in Brazil." Fisheries Research 125: 300-5.

[18] Nguyen, P. M., and Niemeyer, E. D. 2008. "Effects of Nitrogen Fertilization on the Phenolic Composition and Antioxidant Properties of Basil (Ocimum basilicum L.)". Journal of Agricultural and Food Chemistry 56 (18).

[19] Javanmardi, T., Stushnoff, C., Locke, E., and Vivanco, J. M. 2003. "Antioxidant Activity and Total Phenolic Content of Iranian Ocimun accessions." Food Chemistry 83 (4): 547-50.

[20] Jayashinghe, C., Gotoh, N., Aoki, T., and Wada, S. 2003. "Phenolics Composition and Antioxidant Activity of Sweet Basil (Ocimum basilicum L.)." Journal of Agricultural and Food Chemistry 51 (15): 4442-9.

[21] Tarchoune, I., Sgherri, C., Baâtour, O., Izzo, R., Lachaâl, m. F., Navari-Izzo, M. F., and Ouerghi, G. 2012. "Phenolic Acid and Antioxidant Activity in Ocimun basilicum L. Grown under $\mathrm{Na}_{2} \mathrm{SO}_{4}$ Medium." Journal of Medicinal Plants Research 6 (48): 5868-75.

[22] Salas-Perez, L., Fornari-Reale, T., Preciado-Rangel, P., Garcia-Hernandez, J. L., Sanchez-Chavez, E., and Troyo-Dieguez, E. 2018. "Cultivar Variety and Added 
Potassium Influence the Nutraceutical and Antioxidant Content in Hydroponically Grown Basil (Ocimum basilicum L.).” Agronomy-Basel 8 (2): 1-14.

[23] Folch, J., Lee, M., and Sloane Stanley, G. H. 1957. “A Simple Method for Isolation and Purification of Total Lipids from Animal Tissues." Journal of Biological Chemistry 226 (1): 497-509.

[24] Hartman, L. G., and Lago, R. C. A. 1973. "Rapid Preparation of Fatty Acid Methyl Esters from Lipids." Laboratory Practical 22 (6): 457-77.

[25] Hortwiz, W., and Latimer, W. 2005. Official Methods of Analysis of Official Analytical Chemists (18th ed.), Washington: Association of Official Analytical Chemists.

[26] Vyncke, W. 1970. "Direct Determination of the TBA Value in the Trichloroacetic Acid Extract of Fish as a Measure of Oxidative Rancidity." Fette-Seifen Anstrichmittel 72 (12): 1084-7.

[27] Salas-Maldonado, A., Sanchez, M. B., Ruiz, M. A., Koo, F. C., and Torres, H. O. 2009. "Nutritional Information about Some Commercial Fishes from the Peruvian Amazonia." Boletin de Investigacion Instituto Tecnologico del Peru 9: 1-64. (in Spanish)
[28] Strobel, C., Jahreis, G., andKuhnt., K. 2012. "Survey of n-3 and n-6 Polyunsaturated Fatty Acids in Fish and Fish Products." Lipids in Health and Disease 11: 144-54.

[29] Bell, J. G., Preston, T. R., Henderson R. J., Strachan, F., Bron, J. E., Cooper, K., and Morrison, D. J. 2007. "Discrimination of Wild and Cultured European Sea Bass (Dicentrarchus labrax) Using Chemical and Isotopic Analysis." Journal of Agricultural and Food Chemistry 55 (15): 5934-41.

[30] Jankowska, B., Zakes, Z., Zmijewski, T., and Sczepkowski, M. 2010. "Fatty Acid Profile of Muscles, Liver and Mesenteric Fat in Wild and Reared Perch (Percafluviatis L.)." Food Chemistry 118 (3): 764-8.

[31] Fuentes, A., Fernández-Segovia, I., Serra, J. A., and Barat, J. M. 2010. "Comparison of Wild and Cultured Sea Bass (Dicentrarchus labrax) Quality." Food Chemistry 119 (4): 1514-8.

[32] Kaurinovic, B., Popovic, M., Vlaisavlejrvic, S., and Trivic, S. 2011. "Antioxidant Capacity of Ocimunbasilicum L. and Origanum vulgare L. Extracts." Molecules 16 (9): 7401-14. 